\section{Hemoperitoneo por leiomiosarcoma peritoneal}

\section{Sr. Director:}

Los tumores retroperitoneales primitivos representan del 0,05 al $0,2 \%$ del total, siendo principalmente sarcomas malignos. Derivan de los tejidos de origen mesodérmico $(75 \%)$ y neurodérmico $(24 \%)$ o más raramente, de residuos embrionarios $(1 \%)$ $(1,2)$. Entre los tumores de origen mesodérmico, el leiomiosarcoma representa el $23 \%-40 \%$, siendo el más frecuente tras el liposarcoma. Suele desarrollarse entre los 40 y los 60 años, sin existir diferencias entre sexos Clínicamente suele cursar en forma de hemorragia gastrointestinal, masa abdominal palpable, dolor abdominal intermitente y perforación intestinal. Con menor frecuencia producen alteración del estado general, cambios en el hábito intestinal, obstrucción, fiebre y trastornos urinarios $(1,3,4)$. Presentamos por su rareza el caso de un leiomiosarcoma peritoneal de grado intermedio que debutó en forma de hemoperitoneo escasamente sintomático y anemización progresiva.

Se trata de un varón de 84 años con antecedentes de insuficiencia cardiaca, hepatitis no filiada e hipertrofia prostática, que presenta dolor abdominal, deposiciones blandas, tenesmo rectal, fiebre y decaimiento general de una semana de evolución, con episodios intermitentes de similares características, astenia y mínima pérdida de peso desde 8 meses atrás. A la exploración física se apreció TA 91/ 54, palidez cutánea, palpándose una masa periumbilical dolorosa de predominio derecho y leve matidez en flancos. Entre los datos analíticos destacaron: Hb 6,2 g/dl; VCM 85,1; HCM 27,9, VSG 37 mm, Fe 42 $\mathrm{mg} / \mathrm{dl}$, ferritinalS mg/dl; sideremia $24 \mathrm{ng} / \mathrm{dl}$, LDH 530 u/L. Los estudios de orina, marcadores tumorales, proteinograma y radiografías de tórax y abdomen fueron normales o negativos. Una ecografía abdómino-pélvica evidenció una masa de 10x9 $\mathrm{cm}$ con asas intestinales muy engrosadas y fijas en hemiabdomen inferior, con presencia de escasa cantidad de ascitis. Se realizó una TAC abdómino-pélvico que confirmó la existencia de líquido libre abdominal y masa pélvica de 10,6 x 9,4 cm, heterogénea y ubicada entre asas intestinales. Tras laparotomía media se extirpó una masa peritoneal hipogástrica de $525 \mathrm{~g}$ pseudoencapsulada que sangró abundantemente con varios implantes peritoneales y con presencia de sangre en peritoneo. Al corte se observaban extensas áreas necrohemorrágicas con zonas blanquecinas en la periferia, blandas y de aspecto homogéneo. Microscópicamente se observó una neoformación mesenquimal maligna extensamente necrótica, constituida por células fusiformes, con escaso citoplasma y núcleos elongados e hipercromáticos, inmersas en un patrón fibrilar. Existía escasa actividad mitótica (4-7/10 hpf). Los marcadores inmunohistoquímicos realizados (Ker, EMA, VIM, PS100, Act. Lis.) fueron negativos. El fenotipo realizado mostró positividad para actina. Los fragmentos epiploicos remitidos mostraron similar infiltración. Todo ello confirmó el diagnóstico de leiomiosarcoma peritoneal de grado intermedio con implantes periotoneales.

Los leiomiosarcomas presentan al igual que el resto de tumores retroperitoneales una clínica muy inespecífica, lo que explica que el tiempo de diagnóstico sea habitualmente prolongado. En nuestro caso fue la anemización y el sangrado hacia peritoneo lo que motivó que el paciente acudiera al hospital. El diagnóstico de estos tumores se basa principalmente en las pruebas de imagen: ecografía, TAC, RNM, angiografía (muy sensible), urografía y en los hallazgos histopatológicos tras punción-aspiración y cirugía. Se caracterizan por ser tumores muy vascularizados, con áreas de necrosis y formaciones quísticas que pueden fistulizar y perforar hacia la luz intestinal o hacia la cavidad peritoneal, como en nuestro caso. Microscópicamente se observan células tumorales alargadas con cromatina pesada e irregular y paracromatina y membrana del núcleo prominente, pudiendo existir vacuolización del núcleo y el citoplasma y células tumorales no queratinizadas con cabeza bulbosa y citoplasma alargado hacia la cola junto con, células fusiformes, células en raqueta y, ocasionalmente, células binucleadas y multinucleadas con un nucleolo prominente $(3,5)$. La vía de difusión metastásica suele ser la hemática aunque, también puede producir implantes peritoneales por contigüidad e infrecuentemente por vía linfática, siendo el hígado y el peritoneo las localizaciones metastásicas más frecuentes. Las metástasis se encuentran en el $75 \%$ de los tumores mayores de $10 \mathrm{~cm}$. El leiomiosarcoma visceral o retroperitoneal supone la causa más frecuente de metástasis hepática por sarcomas de partes blandas (6).

El tratamiento de elección de los tumores retroperitoneales primarios es la cirugía, siendo la exéresis completa posible sólo en el 33-70\%. El liposarcoma y el sarcoma neurogénico tienen la tasa más alta de resecciones completas mientras que, los leiomiosarcomas son los menos resecables (17-43\%). En un alto porcentaje $(30-86 \%)$, para obtener una exéresis radical la intervención debe ampliarse a uno o más órganos circundantes, principalmente riñón, páncreas e intestino (sobre todo, el colon), bazo y la glándula suprarrenal. La recidiva, incluso en los casos sometidos a resección completa, es muy frecuente (20-87\%). Se produce en un intervalo de 2 a 3 años tras la intervención, con un intervalo medio de 20 meses. La diseminación de la enfermedad es mayoritariamente a nivel local. La frecuencia de las metástasis a distancia varia entre el 3 y el $42 \%$. Los órganos más afectados son el pulmón y el hígado, siendo el leiomiosarcoma, el fibrohistiocitoma maligno y el sarcoma indiferenciado dentro del origen mesodérmico y el neuroblastoma dentro de los neuroectodérmicos los más frecuentes. La escasa respuesta quimioterápica no apoya su uso de forma indiscriminada $(7,8)$. La supervivencia global a los 5 años varía del $15-50 \%$ pero llega a ser del $32-74 \%$ si se limita a considerar los casos sometidos a exéresis completa. Los principales factores pronósticos son la resecabilidad completa del tumor, el grado histológico, el estado general en la presentación inicial de los síntomas, la presencia o no de metástasis, el tamaño tumoral y el estadio. Entre los distintos tipos histológicos de tumores retroperitoneales primitivos, el leiomiosarcoma es el que presenta peor pronóstico, con una nula supervivencia a los 5 años y una supervivencia media de 15 meses $(1,4)$.

\section{Ros, E. Rovira, A. Belda, J. J. Gil Carbó*}

Servicios de Medicina Interna y *Urgencias. Hospital de Sagun to. Sagunto. Valencia

1. Calo PG, Congiu A, Ferreli C, Nicolosi A, Tarquini A. Primary retroperitoneal tumors our experience. Minerva Chir 1994; 49: 4349.

2. Paron L, Vottero G, Cardino L. Retroperitoneal leiomyosarcoma originated from inferior vena cava. Case report. Minerva Chir 1995; 50: 603-5.

3. Hsu CY, Yang CH. Cytology of metastasic leimyosarcoma. Acta Cytol 1995; 39: 1247-1252.

4. Chou FF, Eng HL, Sheen-Chen SM. Smooth muscle tumors of the gastrointestinal tract: analysisofprognosticfactors. Surgery 1996;119: 171-7.

5. Suster S, Wong TY, Moran CA. Sarcomas with combined features of liposarcoma and leiomyosarcoma. Study of two cases of an unusual sofctissue tumor showing dual lineage differentiation. Am J Surg Pathol 1993; 17: 905-911.

6. Medici F, Mingoli A, Mingazzini P, Bartolucci P, Nardacchione F, Sgarzini G, Modini C. Small bowel leiomysarcomas. Minerva Chir 1993; 48 : 1219-22.

7. Jaques DP, Coit DG, Casper ES, Brennan MF. Hepatic metastases from so-tissue sarcoma. Ann Surg 1995; 221(4): 392-397.

8. Karakousis CP, Blumenson LE, Canavase G, Rao U. Surgery for disseminated abdominal sarcoma. Am J Surg 1992; 163: 560-564. 